ORIGINAL ARTICLE

\title{
Socio-demographic Status \& Associated Risk Factors of the Stroke Patient's in a Tertiary Care Hospital of Bangladesh
}

\author{
*MR Siddiqui ${ }^{1}$, QT Islam ${ }^{2}$, MJ Iqbal ${ }^{3}$, SS Binte-Mosharraf ${ }^{4}$ \\ ${ }^{1}$ Dr. Mahmudur Rahman Siddiqui, Assistant Professor, Department of Medicine, Anwer Khan Modern \\ Medical College \& Hospital, Dhaka.dr.mahmud99@yahoo.com \\ ${ }^{2}$ Prof. Dr. Quazi Tarikul Islam, Professor, Department of Medicine, Popular Medical College \& \\ Hospital, Dhaka \\ ${ }^{3}$ Dr. Md. Jabed Iqbal, Junior Consultant, Department of Cardiology, Anwer Khan Modern Medical \\ College \& Hospital, Dhaka \\ ${ }^{4}$ Dr. Sumaiya Sultana Binte-Mosharraf, Postgraduate resident, National Institute of Ophthalmology \& \\ Hospital, Dhaka \\ *Corresponding author
}

\begin{abstract}
Stroke is the most common neurological emergency. A total number of 100 randomly selected, clinically and CT proven acute stroke patients were studied at medicine units of Dhaka Medical College Hospital. Socio-demographic data and major risk factors or co-morbid conditions among acute stroke patient were identified and correlated. Out of 100 patients $29 \%$ were in between 51 60 years age group \& $72 \%$ were male and $28 \%$ were female patients. In this series $24 \%$ were illiterate. Of the literate group 39\% went to primary school, $20 \%$ completed SSC, $8 \%$ completed HSC, $5 \%$ completed graduation and only $4 \%$ completed post-graduation. Majority of the patients were unemployed (22\%). Other was businessman (20\%), housewife (19\%) and cultivator $(16 \%) .63 \%$ percentage of the patients from low income group, which was followed by middle income group (33\%). Majority 53\% patients had Ischaemic stroke, $45 \%$ Intracerebral haemorrhage (ICH) and only 2\% had Subarachnoid haemorrhage (SAH). $77 \%$ of patient had history of hypertension, 22\% Diabetes mellitus, 20\% Dyslipidaemia, 13\% Previous Stroke, 27\% Ischaemic heart disease. Out of 77 hypertensive stroke patients $37(48.05 \%)$ had haemorrhagic stroke \& 40(51.94\%) had ischemic stroke.
\end{abstract}

Key words: Stroke, socio-demographic data, co-morbidity

\section{Introduction}

Stroke is the most common neurological emergency ${ }^{1}$. Stroke is the third most common cause of death in developed nations after ischaemic heart disease and cancer ${ }^{2}$. The AHA estimates that 780000 strokes occur each year; $6,00,000$ of these are new strokes, and 1,80,000 are recurrent strokes ${ }^{3}$. According to year book of the department of Medicine at DMCH (2009) $14.7 \%$ of total admission was stroke patients. In Bangladesh about $40 \%-50 \%$ of beds are occupied by stroke patients in the neurology ward. Stroke is a complex disease that requires

the efforts and skills of all members of the multidisciplinary team ${ }^{4}$. A coordinated care of the stroke patient results in improved outcomes, decreased lengths of stay, and decreased costs 5 . In 2004, the cost of stroke was estimated at $\$ 53.6$ billion (direct and indirect costs), with a mean lifetime cost estimated at $\$ 140 \quad 048 .^{6}$ Stroke is also a leading cause of functional impairments, with $20 \%$ of survivors requiring institutional care after 3 months and $15 \%$ to $30 \%$ being permanently disabled ${ }^{6}$. Stroke is a life changing event that affects not only the

AKMMC J 2013; 4(2): 18-22 
MR Siddiqui, QT Islam, MJ Iqbal et al

person who may be disabled, but the entire family and other caregivers as well. Stroke patient die off either due to the primary disease or due to complications. But developing country like Bangladesh, low income status and low educational background are the great problem to manage stroke patients. Disease like stroke requires longer time and financial support to manage. But most of the stroke patients in tertiary level government hospital of Bangladesh come from low socioeconomic status. They have less awareness about the preventable risk factor of stroke ${ }^{7}$. Despite the advent of treatment of selected patients with acute stroke, effective prevention remains the best treatment for reducing the burden of stroke. The relationship between socio-demographic and clinical factor has been less well studied. In this study, I attempted to find out the common sociodemographic data and co-morbid conditions in acute stroke patients in a tertiary care hospital of Bangladesh.

\section{Materials \& Methods}

In this descriptive cross sectional study, a total number of 100 randomly selected, clinically and CT proven acute stroke patients were studied from Jan 2010 to June 2010 at medicine units of Dhaka Medical College Hospital. Patient admitted within 48 hours of the onset of stroke with CT scan of the brain showing infarct or haemorrhage was enrolled for this study. Sociodemographic data and co-morbidity (risk factor) among acute stroke patient were identified and correlated. All data were collected in individual case record form. This was done by detailed history from patients or his / her relatives, complete physical examination and necessary investigations. Statistical analysis was carried out by using SPSS v16.0 Windows statistical software. Descriptive statistics were used for the interpretation of the findings. Informed and written consent obtained from all patients or their guardian. Formal Ethical Clearance was obtained from the Research Review Committee of Dhaka Medical College and Hospital.

\section{Results}

Out of 100 patients, majority $53 \%$ patients had ischaemic stroke, $45 \%$ had intracerebral haemorrhage and only $2 \%$ had subarachnoid haemorrhage.

Table 1: Distribution of patients in relation to age \& sex group $(\mathrm{n}=100)$

\begin{tabular}{cccc}
\hline \multirow{2}{*}{$\begin{array}{c}\text { Age groups } \\
\text { (years) }\end{array}$} & \multicolumn{2}{c}{ Sex of the patient } & Total number \\
\cline { 2 - 3 } & Male & Female & $(\%)$ \\
\hline $21-30$ & 1 & 1 & $2(2)$ \\
$31-40$ & 8 & 3 & $11(11)$ \\
$41-50$ & 13 & 5 & $18(18)$ \\
$51-60$ & 21 & 8 & $29(29)$ \\
$61-70$ & 16 & 6 & $22(22)$ \\
$71-80$ & 7 & 4 & $11(11)$ \\
$81-90$ & 5 & 0 & $5(5)$ \\
$91-100$ & 1 & 1 & $2(2)$ \\
Total & 72 & 28 & $100(100)$ \\
\hline n: Number of the patient & & \\
\hline
\end{tabular}

Table 1 shows that maximum number of patients (29\%) in this study were in between 51-60 years age group followed by (22\%) between 61-70 years age group. The maximum number of male $(21 \% \& 16 \%)$ and female $(8 \% \& 6 \%)$ were also in the above age group respectively.

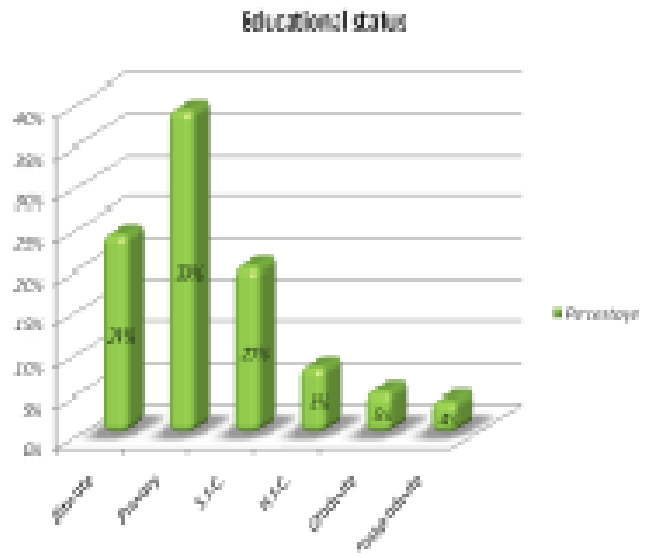

Figure 1. Distribution of the patients in educational categories

The above figure shows that in this series $24 \%$ were illiterate. Of the literate group 39\% went to primary school, $20 \%$ completed SSC, $8 \%$ completed HSC, $5 \%$ completed graduation and only $4 \%$ completed post-graduation, 
Socio-demographic Status \& Associated Risk Factors

Table 2: Distribution of patients in occupational categories $(\mathrm{n}=100)$

\begin{tabular}{|c|c|c|}
\hline Occupation & Number of pati ents & Percentage (\%) \\
\hline Service & 12 & 12.0 \\
\hline Business & 20 & 20.0 \\
\hline Student & 2 & 2.0 \\
\hline Labour & 7 & 7.0 \\
\hline Cultivator & 16 & 16.0 \\
\hline Housewife & 19 & 19.0 \\
\hline Unemployed & 22 & 22.0 \\
\hline Other & 2 & 2.0 \\
\hline Total & 100 & 100.0 \\
\hline
\end{tabular}

The above table shows that the majority patients were unemployed $(22 \%)$. Other was business $(20 \%)$, housewife (19\%) and cultivator $(16 \%)$.

Table 3: Economic status of the patients $(n=100)$

\begin{tabular}{lcc} 
Income status & Number of patients & Percentage (\%) \\
\hline $\begin{array}{l}\text { Low (Less than Tk. 60,000/=per } \\
\text { annum) }\end{array}$ & 63 & 63 \\
$\begin{array}{l}\text { Middle (From Tk. 60,000 Tk. } \\
\text { 1,80,000/=per annum) }\end{array}$ & 33 & 33 \\
High ( > Tk. 180,000) & 4 & 4 \\
Total & 100 & $100 \%$ \\
\hline $\begin{array}{l}\text { N: number of patients, this income status classification was according to } \\
\text { Bangladesh Bureau of Statistics. }\end{array}$ \\
\hline
\end{tabular}

Table 3 shows that the low income group (63\%) omprises the major percentage of the patients, which was followed by middle income group (33\%).

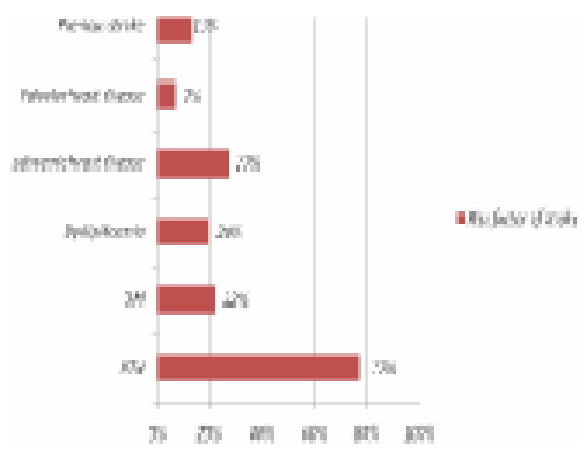

Figure 2 Association of the risk factor of stroke

Figure 2 shows that about $77 \%$ of patient had history of hypertension, $22 \%$ Diabetes mellitus, $20 \%$ Dyslipidaemia, $13 \%$ Stroke, $27 \%$ Ischaemic heart disease.
Table 4 Association of hypertension with different type of stroke $(\mathrm{n}=98)$

\begin{tabular}{lcccc}
\hline Type of Stroke & $\begin{array}{c}\text { Hypertensive } \\
(\%)\end{array}$ & $\begin{array}{c}\text { Normotensive } \\
(\%)\end{array}$ & Total & $\mathrm{p}$ value \\
\hline Haemorrhagic & $37(48.05)$ & $10(43.47)$ & 47 & \\
Ischaemic & $40(51.94)$ & $13(56.52)$ & 53 & $>0.05$ \\
Total & $77(100)$ & $23(100)$ & 100 & \\
\hline n: number of patient, & & & \\
\hline
\end{tabular}

This table shows that out of 77 hypertensive stroke patients $37(48.05 \%)$ had haemorrhagic stroke \& $40(51.94 \%)$ had ischemic stroke. Chisquare test $(\chi 2)$ was done to measure the level of significant ( $\mathrm{p}$ value). $\chi 2=0.068, \mathrm{df}=1, \mathrm{p}=$ $>0.05$. There is no significant association between hypertension and type of stroke.

Table 5: Association of irregular antihypertensive medication with different type of stroke $(n=75)$

\begin{tabular}{lcccc}
\hline $\begin{array}{c}\text { Antihypertensiv } \\
\text { Medication }\end{array}$ & $\begin{array}{c}\text { Hemorrhage } \\
(\%)\end{array}$ & Ischemic $(\%$, & Total & p value \\
\hline $\begin{array}{l}\text { On irregular or } \\
\text { no medication }\end{array}$ & $28(75.67)$ & $26(65)$ & $54(70.12)$ & \\
$\begin{array}{l}\text { On regular } \\
\text { medication } \\
\text { Total }\end{array}$ & $9(24.32)$ & $14(35)$ & $23(29.87)$ & $>0.05$ \\
& $37(100)$ & $40(100)$ & $77(100)$ & \\
\hline n: number of patient, & & & \\
\hline
\end{tabular}

This table shows, out of 37 hypertensive haemorrhagic stroke patients $28(75.67 \%)$ were on irregular or no antihypertensive medications and among 40 hypertensive ischaemic stroke patients $26(65 \%)$ were on irregular or no antihypertensive medications. Chi-square test $\left(\left(\chi^{2}\right)\right.$ was done to measure the level of significant ( $\mathrm{p}$ value). $\chi^{2}=0.74$, $\mathrm{df}=1, \mathrm{p}=$ $>0.05$. There is no significant association between taking of irregular or no antihypertensive medication and type of stroke.

Table 6: Association of stroke with Diabetes mellitus $(n=22)$

\begin{tabular}{lccc}
\hline Diabetes mellitus & Number of patis & Percentage $(\%$, & p value \\
\hline Diabetic & 22 & 22.00 & \\
Non diabetic & 78 & 78.00 & $>0.05$ \\
& 100 & 100.00 & \\
Total & & & \\
\hline
\end{tabular}

The table shows that, out of 100 stroke patients $22(22 \%)$ were diabetic. Chi-square test $\left(\chi^{2}\right)$ was done to measure the level of significant ( $p$ value). $\chi^{2}=0.74, \mathrm{df}=1, \mathrm{p}=>0.05$. There is no significant association between stroke and diabetes mellitus. 
MR Siddiqui, QT Islam, MJ Iqbal et al

\section{Discussion}

Stroke incidence rises exponentially with increasing age. In this present study, (table-1) all the patients were grouped in eight age groups. Majority of the study subjects were above the 40 years of age. The maximum number of patients $(29 \%)$ in this study were in between 51-60 years age group followed by $(22 \%)$ between $61-70$ years age group. The maximum number of male $(21 \%$ \& $16 \%)$ and female $(8 \% \& 6 \%)$ were also in the above age group respectively. Bevan $\mathrm{H}$ et $\mathrm{al}^{8}$ in his study of stroke also found similar picture. A hospital based study done in $\mathrm{DMCH}$ showed that only $1 \%$ occurred in $<20$ years and $26 \%$ in $20-45$ years and majority are above 45 years. ${ }^{9}$ Bell et al 10 studied with stroke where most of the incidence of stroke was between the age of 5069 years. Abdul Basher studied 100 patients of stroke in our country where highest incidence were between 5th to 7th decades. A study done by Chowdhury SZM ${ }^{11}$ and Arif $\mathrm{SM}^{12}$ also found peak incidence between 5 th to 7 th decades. So, the present study coincides with all above studies. $72 \%$ were male and $28 \%$ were female i.e., male incidence is $30 \%$ higher than female which coincide with international study. The present study coincides with the study of Chowdhury et al, ${ }^{11}$ and Kurtzke, ${ }^{13}$ where showed that frequency of stroke is $30 \%$ higher in men than women. CT scan findings of the studied patients show that majority $53 \%$ patients had ischaemic stroke, $45 \%$ had intracerebral haemorrhage and only $2 \%$ had subarachnoid haemorrhage. This study similar with study of Alam B et al, ${ }^{14}$ they studied 1020 patients of stroke in DMCH. In their study the incidence of Ischaemic stroke was $57.84 \%$ and haemorrhagic stroke was $42.16 \%$. But this study contradicts study of Hayee et al, ${ }^{15}$ which was also done in $\mathrm{DMCH}$ where the incidence of ischaemic stroke was $83.89 \%$ higher rate of haemorrhagic stroke is also have been reported in number of hospital series in Asian countries. Higher rate of haemorrhagic stroke in this present hospital based study and previous Alam B et al ${ }^{14}$ study in $\mathrm{DMCH}$ may be due to the acute admission is more related to the haemorrhagic stroke. In this series (figure-1) $24 \%$ were illiterate. Of the literate group $39 \%$ went to primary school, $20 \%$ completed SSC, 8\% completed HSC, 5\% completed graduation and only $4 \%$ completed post-graduation. Majority of the patients in our study were completed only primary school or illiterate because majority patients reported in $\mathrm{DMCH}$ came from low socioeconomic status. The low income group (63\%) comprises the major percentage of the patients in our study (table-3). majority patients were unemployed $(22 \%)$. Other was business $(20 \%)$, housewife $(19 \%)$ and cultivator $(16 \%)$, which was similar to the study of Hakim $\mathrm{M}$ et al ${ }^{16}$ in the medicine unit of BSMMU, BIRDEM, SSMCH and $\mathrm{DMCH}$. Present study shows that (table-4,5) $77 \% \quad(p<0.05) \quad$ stroke patients were hypertensive. Among them 37(48.05\%) hypertensive patients had haemorrhagic stroke and $40(51.94 \%)$ hypertensive patients had ischaemic stroke, but there was no statistic significant association between hypertension and type of stroke $(p>0.05)$. Table-3.6 shows, out of 37 hypertensive haemorrhagic stroke patients $28(75.67 \%)$ were on irregular or no antihypertensive medications and among 40 hypertensive ischaemic stroke patients $26(65 \%)$ were on irregular or no antihypertensive medications. Chances of stroke were more among hypertensive patient on irregular medications, but chi-square $\left(\mathrm{X}^{2}\right)$ revealed no significant result $(p=>0.05)$. This present study is almost similar with the stroke of Chowdhury et al, ${ }^{11}$ who studied 74 hypertensive patients who suffered stroke and had shown that $34 \%$ of the patients were not aware that they were hypertensive and $60.7 \%$ were on irregular treatment. Bevan et al, 8 in his study showed that $31 \%$ of the patient with cerebral infarct had HTN. This present study correlates with the studies. Out of 100 stroke patients 22 were diabetic. Among diabetic $77.27 \%$ was previously diagnosed, $22.72 \%$ was newly diagnosed on admission. The Copenhagen stroke study has shown that in 1135 acute stroke patients, 233(20\%) were suffering diabetes, ${ }^{17}$ which is similar to our result. 
Socio-demographic Status \& Associated Risk Factors

\section{Conclusion}

Stroke is one of the foremost causes of morbidity, mortality and a socioeconomic challenge, more so in Bangladesh where health system including the rehabilitation is not within the reach of ordinary people. It is obvious that, this devastating condition not only affects the patient but also their family. This study may have not reflected the exact situation, but can give an utmost picture of the disease in a tertiary care hospital of Bangladesh. In a developing country like ours, the best policy for combating stroke is primary prevention. A much larger scale study must be done in various level of hospital in our country to find out the actual picture.

Conflict of Interest: We have no conflict of interest.

Acknowledgement: Dr. Ahmed Hossain \& Dr. Yousuf Ur Rahman for their support.

\section{Reference}

1. Bergen DC. The world wide burden of neurologic disease. Neurology 1996; 47: 21-50.

2. Allen CMC, Lueck CJ, Dennis M. Neurological disease. In Nicholas AB (ed). Davidson's Principal and Practice of Medicine, 20th edition. UK Churchill Livingstone Elsevier, 2006; 1131-1235.

3. Rosamond W, Flegal K, Furie K et al. Heart disease and stroke statistics: 2008 update: a report from the American Heart Association Statistics Committee and Stroke Statistics Subcommittee. Circulation 2008; 117: 25-146.

4. Summers D, Leonard A, Wentworth D et al. Comprehensive Overview of Nursing and Interdisciplinary Care of the Acute Ischemic Stroke Patient. A Scientific Statement from the American Heart Association. Stroke 2009; 40: 2911-44.

5. Alberts MJ, Hademenos G, Latchaw RE et al. Recommendations for the establishment of primary stroke centers: Brain Attack Coalition. JAMA 2000; 283: 3102-09.
6. American Heart Association. Heart Disease and Stroke Statistics-2004 Update. Dallas, Tex: American Heart Association; 2003.

7. Adams H, Adams R, Del Zoppo G et al. Stroke Council of the American Heart Association; American Stroke Assocation. Guidelines for the early management of patients with ischemic stroke: 2005 guidelines update: a scientific statement from the Stroke Council of the American Heart Association/American Stroke Association (published corrections appear in Stroke 2005; 36: 1626 and Stroke. 2005; 36: 1352). Stroke 2005; 36: $916-23$.

8. Bevan H, Sharma K, Bradly W. Stroke in young adults. Stroke 1990;21:382-86.

9. Mohammad QD, Alam B, Habib M et al. Prevalence of stroke in Bangladeshi population-A population based study. JAFMC 2009; 5(1): 24-7.

10. Bell DA, Brien W, Vladimar $\mathrm{H}$ et al. Antiphospholipid synd: prevalence among patients with stroke and TIA. Am J Med 1990; 88: 593-97.

11. Chowdhury SZM. Study of risk factor in cerebrovascular disease- A study of 100 cases (Dissertation). BCPS 1991: 48.

12. Arif SM. Study on risk factor for stroke in Bangladesh (Dissertation). BCPS 1993:55.

13. Kurzke JF. Epidemiology of cerebrovascular disease. In :P.Rowland L, editor. Merrtt's Neurology. Philadelphia: LLW; 2000: 135-76.

14. Alam B, Mohammad QD, Habib M et al. Stroke evaluation risk factor. Bangladesh $\mathrm{J}$ of Neuroscience 1999; 15(2): 14-8.

15. Hayee MA, Anwarullah AKM, Haque A et al. Analysis of risk factor of stroke in 472 cases. Bangladesh Journal of Neuroscience 1998; 14(2): 41-54.

16. Hakim M, Hayee MA, Saha CK et al. Sociodemographic study of posterior circulation stroke survival. JCMCTA 2009; 20(1): 23-6.

17. Boysen G, Nyboe J, Appleyard M et al. Stroke incidence and risk factors for stroke in Copenhagen, Denmark. Stroke 1988; 19: 1345-53. 